\title{
A valid two-item food security questionnaire for screening HIV-1 infected patients in a clinical setting
}

Jessica Young ${ }^{1,2}$, Sarangapany Jeganathan ${ }^{1,2, *}$, Louise Houtzager ${ }^{1,2}$, Aaron Di Guilmi ${ }^{1,3}$ and Julianita Purnomo ${ }^{1}$

'Albion Street Centre, Prince of Wales Hospital, 150-154 Albion Street, Surry Hills, Sydney, NSW 2010, Australia: ${ }^{2}$ Faculty of Health and Behavioural Science, University of Wollongong, Wollongong, Australia:

${ }^{3}$ School of Molecular and Microbial Biosciences, University of Sydney, Sydney, Australia

Submitted 10 September 2008: Accepted 6 April 2009: First published online 28 May 2009

\begin{abstract}
Objective: To validate a two-item food security questionnaire (FSQ) for use in a clinical setting to screen HIV-1 infected patients for food insecurity.

Design: The present study was a questionnaire-based survey of forty-nine subjects attending an HIV clinic. Subjects completed a two-item questionnaire and a six-item validated FSQ contemporaneously.

Results: A strong correlation was found between the two-item and six-item FSQ $(\rho=0 \cdot 895 ; 95 \%$ CI 0.821, 0.940; $P<0 \cdot 0001)$. Cronbach's $\alpha$ coefficient was found to be 0.94 and 0.90 for the two-item and six-item FSQ, respectively. The two-item FSQ yielded a sensitivity of $100 \%(95 \%$ CI 75,100$)$ and a specificity of $78 \%(95 \%$ CI 61, 90). The negative predictive value was found to be $100 \%(95 \%$ CI 88, 100). Conclusions: The results of the present study suggest that the two-item FSQ is a valid, reliable and sensitive screening tool of food insecurity in people living with HIV in a clinical setting.
\end{abstract}

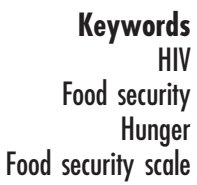

Food insecurity has been defined as the 'limited or uncertain availability of nutritionally adequate and safe food, or limited or uncertain ability to acquire acceptable food in socially acceptable ways ${ }^{\prime(1)}$. Food and nutrition insecurity have been linked worldwide to the transmission of HIV and poor outcomes related to HIV disease ${ }^{(2)}$. Other consequences of food insecurity include poor nutritional status, which may hasten progression of the disease, undermine adherence and response to antiretroviral therapy (ART) and exacerbate socio-economic impacts of the virus ${ }^{(3)}$. Despite this, food insecurity and nutrition remain a problem among people living with HIV (PLHIV) ${ }^{(4)}$.

Food security (FS) can be assessed by a range of methodologies, including a face-to-face interview and questionnaires. A number of questionnaires have been used in the past ${ }^{(1-7)}$. Some of these were long and time consuming for patients to complete, and a modified version six-item FS questionnaire (FSQ) was subsequently developed and validated to measure food security in American households ${ }^{(5,8)}$. This tool, while useful, may be limited by time constraints on patients completing a multidisciplinary nutrition-screening tool (MNST) incorporating other medical and related specialities.

Nutritional deficiencies are common in HIV patients and are multifactorial, involving biological and psychosocial issues. In our centre, we manage PLHIV with a multi- disciplinary approach involving medical, psychological and nutrition interventions. A MNST has been developed for ongoing patient care at our centre. The MNST incorporates screening for symptoms, malnutrition, cardiovascular and diabetes risk, food security, oral health and mental health.

The aim of the present study was to validate a two-item FSQ with the six-item questionnaire validated by Blumberg et $a l^{(5)}$ for the purposes of screening in a clinical setting for food insecurity in a population of adults living with HIV in Australia.

\section{Method}

The present study was approved by the Institutional Ethics Committee, in 2007. The study group consisted of a convenience sample of forty-nine participants attending the Albion Street Centre, a large multidisciplinary government funded HIV ambulatory care centre in Sydney, Australia, for routine HIV care between September 2007 and February 2009. The Centre provides care for HIV infected individuals representing a range of socioeconomic backgrounds. Inclusion criteria for participation included people over the age of 18 years, with a known HIV infection.

Each participant completed the abridged two-item FSQ, as well as the six-item FSQ, contemporaneously. 
The two-item FSQ was part of a larger study in which participants completed a variety of questionnaires including: (i) a Demographics questionnaire; and (ii) a Multidisciplinary screening tool incorporating questionnaires on (a) Symptoms, (b) Malnutrition, (c) Cardiovascular and diabetes risk, (d) Food security, (e) Depression screening and (f) Oral health screening. As the aim of the larger study was to assess the usefulness of the larger MNST to screen for nutritional, dental and psychological problems, it was necessary to administer the two-item FSQ and the six-item FSQ as separate documents on the same visit to determine if the former was as reliable as the full six-item questionnaire in detecting difficulties with food security in this population.

The six-item FSQ consists of three compulsory screening questions with an affirmative answer requiring a patient to answer three additional questions. Scores were obtained by summing the responses according to the tool scoring guidelines. Each affirmative answer, either 'sometimes true' or 'often true', scored 1 and 'never true' scored 0 . The scores ranged from 0 to 6 based on the number of affirmative responses. A score of $\leq 1$ indicates food security, 2 to 4 food insecurity without hunger and $\geq 5$ food insecurity with hunger ${ }^{(7)}$.

The two questions for food security (Appendix) were taken directly from the six-item FSQ and used the same scoring as the six-item questionnaire ${ }^{(5)}$. The total score for the two questions ranged from 0 to 2. An affirmative answer to either question in the two-item FSQ indicated a dietetic referral.

\section{Statistical analysis}

Statistical analysis was performed using the Statistical Package for Social Sciences (SPSS Inc., Chicago, IL, USA). Validity was assessed using Spearman's correlation coefficient test. Reliability was tested using Cronbach's $\alpha$ coefficient. An $\alpha$ value of $>0.70$ was considered good internal reliability. Sensitivity and specificity were analysed using cross tabulation. The total score of the two-item and sixitem FSQ was converted to a binary score using a cut-off of $>0$ equal 1 and $\geq 2$ equal 1 for the two-item and sixitem questionnaire, respectively. Concurrence of identifying food insecurity was determined using the kappa statistic. All tests were two-sided with a significance level of $<0 \cdot 05$.

\section{Results}

Forty-nine subjects (forty-seven males and two females) with a mean age of 44.6 (SD 9.5) years, and thirty-nine ( $80 \%$ ) of Caucasian origin were enrolled to the study. The mean duration of HIV infection was $12 \cdot 1$ (SD 7.3) years, and thirty-six (74\%) were currently receiving ART medication. Thirty-five (71\%), of the participants had at least a tertiary (including technical) education, with thirty-one (63\%) employed either full-time or part-time.

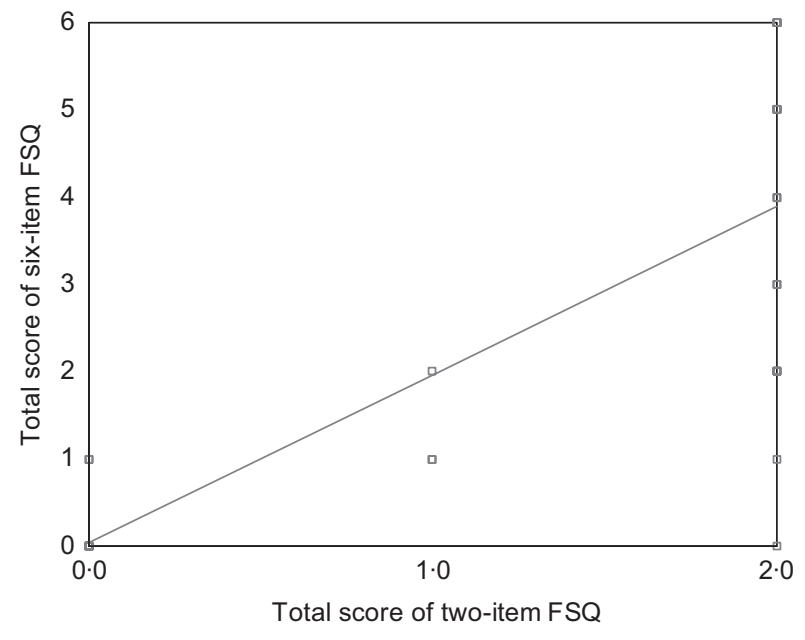

Fig. 1 Relationship between the abridged two-item food security questionnaire (FSQ) and the six-item FSQ

Only seven (14\%) were living in assisted rent or rent-free accommodation.

There were no missing or refusal responses. A statistically significant correlation $(\rho=0 \cdot 895 ; 95 \%$ CI $0 \cdot 821,0 \cdot 940$; $P<0 \cdot 0001)$ was found between the abridged two-item FSQ and the six-item FSQ (Fig. 1). The $\kappa$ agreement of the responses between the two questionnaires for food insecurity was $0.650(P<0 \cdot 0001)$. The internal reliability of the two-item and six-item FSQ, as determined by Cronbach's $\alpha$ coefficient, was found to be 0.94 and 0.90 , respectively. The two-item FSQ yielded a sensitivity of $100 \%$ (95\% CI 75, 100), specificity 78\% (95\% CI 61, 90) and a negative predictive value of $100 \%$ (95\% CI 88, 100).

\section{Discussion}

The present study found a significant positive correlation between the two-item and the six-item FSQ completed by participants. The validity is further supported by a high level of concurrence between the questionnaires to detect food insecurity. This study also found the internal reliability of the two-item FSQ, to be $0 \cdot 94$, which was higher than the six-item FSQ, indicating excellent internal reliability. A single-item FSQ, previously tested, found very low sensitivity but high specificity indicating that it was not an ideal screener ${ }^{(9)}$. In contrast, this two-item FSQ was found to be a highly sensitive tool with good specificity and high negative predictive value, suggesting that the two-item FSQ met the criteria for an ideal screening tool for food security in a clinical setting for PLHIV.

The prevalence of food insecurity worldwide ranges from less than $5 \%$ in some countries to greater than $35 \%$ in resource-poor countries ${ }^{(10)}$. In developed countries such as Australia, the United States and Canada, the prevalence of food insecurity was reported as $5 \%$ to $8 \%$, $10 \cdot 9 \%$ and $14.9 \%$, respectively ${ }^{(11-13)}$. The HIV Futures 5 
Survey reported $52 \%$ of PLHIV in Australia to be food insecure, an estimated seven times higher than the general population. In the same study, $14 \%$ of respondents reported paying for the cost of food as "very difficult $^{\text {(14) }}$. Similar findings have been reported in a Canadian HIV cohort study ${ }^{(4)}$. These findings are important as food insecurity is not considered a problem in developed countries such as Australia due to its abundant food supply and well-established social security safety net $^{(15)}$. The HIV Futures 5 has also reported that $28 \%$ of PLHIV are living below the poverty line in Australia, reinforcing the need to screen HIV patients for food insecurity in developed countries ${ }^{(14)}$.

There are limitations to the present study in regards to the small sample size and the non-random method of sampling. However, it has been reported that a very large correlation of $0.7-0.9$ requires a sample size of about forty-six if the CI is 0.20 or less ${ }^{(16)}$. In the present study, the CI was found to be $0 \cdot 12$. Therefore, this finding with the similarity of the demographics of our cohort to a larger national Australian study, which is representative of adults living with $\mathrm{HIV}^{(14)}$, are suggestive that this two-item FSQ may be used as a screener among PLHIV in Australia but may require further validation with a larger representative sample. We also acknowledge that a $5 \%$ bias in both sensitivity and specificity caused by data-driven selection on a small sample is a limitation. However, a simulation study has shown that the nearer the true values were to $100 \%$ the less room there is for an overestimation ${ }^{(17)}$.

In conclusion, the present study found the two-item FSQ to be a valid, reliable, sensitive, simple and easyto-use tool for clinical use in PLHIV to identify food insecurity. Appropriate referral to a dietitian for nutrition counselling can reduce the impact of food insecurity in the lives of PLHIV by providing individualised evidencebased advice.

\section{Acknowledgements}

There were no external sources of funding as the present study was done as a thesis for the university for Miss Jessica Young and she is a member of the Nutrition Screening Study team. The authors have no conflict of interests to declare. The contributions of each author in this work are as follows: J.Y. - as above, design, data collection, analysis and writing the paper; S.J. - Supervisor, member of the study team and writing of paper; L.H. - Supervisor, member of the study team and writing of paper; A.D.G. - involved in design, data collection and member of the study team; J.P. - involved in design, data collection and member of the study team. The authors would like to thank Dr Kim Begley and Dr Marijka Batterham for their valuable advice in the preparation of the manuscript. The authors would also like to thank the doctors, nurses, dietitians and clients of Albion Street Centre who participated in the study.

\section{References}

1. Carlson SJ, Andrews MS \& Bickel GW (1999) Measuring food insecurity and hunger in the United States: development of a national benchmark measure and prevalence estimates. J Nutr 129, Suppl., 510S-516S.

2. Fields-Gardner C \& Fergusson P, American Dietetic Association, Dietitians of Canada (2004) Position of the American Dietetic Association and Dietitians of Canada: nutrition intervention in the care of persons with human immunodeficiency virus infection. J Am Diet Assoc 104, $1425-1441$.

3. Kendall A, Olson CM \& Frongillo EA Jr (1995) Validation of the Radimer/Cornell measures of hunger and food insecurity. J Nutr 125, 2793-2801.

4. Normen L, Chan K, Braiststein P, Anema A, Bondy G, Montaner JS \& Hogg RS (2005) Food insecurity and hunger are prevalent among HIV-positive individuals in British Columbia, Canada. J Nutr 135, 820-825.

5. Blumberg SJ, Bialostosky K, Hamilton WL \& Briefel RR (1999) The effectiveness of a short form of the Household Food Security Scale. Am J Public Health 89, 1231-1234.

6. Frongillo EA Jr, Rauschenbach BS, Olson CM, Kendall A \& Colmenares AG (1997) Questionnaire-based measures are valid for the identification of rural households with hunger and food insecurity. J Nutr 127, 699-705.

7. Bickel G, Nord M, Price C, Hamilton WL \& Cook JT (2000) Guide to Measuring Housebold Food Security. Revised. Alexandria, VA: US Department of Agriculture, Food and Nutrition Service; available at http://www.fns.usda.gov/ fsec/files/fsguide.pdf

8. Gulliford MC, Mahabir D \& Rocke B (2004) Reliability and validity of a short form household food security scale in a Caribbean community. BMC Public Health 4, 22.

9. Nolan $M$, Williams $M$, Rickard-Bell $G$ \& Mohsin $M$ (2006) Food insecurity in three socially disadvantaged localities in Sydney, Australia. Health Promot J Aust 17, $247-254$

10. Food and Agriculture Organization of the United Nations (2006) The State of Insecurity in the World: Eradicating World Hunger - Taking Stock Ten Years after the World Food Summit. Rome: FAO Corporate Document Repository, Economic and Social Department; available at http:// www.fao.org/docrep/009/a0750e/a0750e00.htm

11. Booth S \& Smith A (2001) Food security and poverty in Australia - challenges for dietitians. Aust J Nutr Diet 58, 150-156.

12. Mark N, Andrews M \& Carlson S (2007) Household Food Security in the United States, 2006. ERR-49. http://www. ers.usda.gov/publications/err49 (accessed December 2008).

13. Health Canada (2007) Community Health Survey, Cycle 2.2, Nutrition (2004) - Income-Related Household Food Security in Canada. Ottawa: Health Canada; available at http://www.hc-sc.gc.ca/fn-an/surveill/nutrition/commun/ index_e.html

14. Grierson J, Thorpe R \& Pitts M (2006) HIV Futures Five: Life as We Know It. Melbourne: LaTrobe University, The Australian Research Centre in Sex, Health and Society; available at http://www.latrobe.edu.au/hivfutures/HIV\% 20Futures\%205\%20Report.pdf

15. Dietitions Association of Australia. Food security. http:// www.daa.asn.au/index.asp?PageID $=2145834445$ (accessed September 2008).

16. Hopkins WG. A new view of statistics: Sample size 'On the fly'. Internet Society for Sport Science. http://www.sportsci. org/resource/stats/ssonthefly.html (accessed March 2009).

17. Leeflang MM, Moons KG, Reitsma JB \& Zwinderman AH (2008) Bias in sensitivity and specificity caused by datadriven selection of optimal cutoff values: mechanisms, magnitude, and solutions. Clin Chem 54, 729-737. 


\section{Appendix}

Please read the following two statements and indicate whether the statement was OFTEN, SOMETIMES or NEVER true for you or other members of your household in the last 12 months.

1. The food I/we bought just didn't last, and I/we didn't have money to get more.

Never true

Sometimes true

Often true

2. I/we couldn't afford to eat balanced meals.

Never true

Sometimes true

Often true 